\title{
STUDENT'S CONCEPTS OF AND APPROACHES TO LEARNING AND THE RELATIONSHIPS BETWEEN THEM
}

\author{
Mohammad Ahmad Alkhateeb*, Osamah Abdel Qader Bani Milhem** \\ The Hashemite University, Jordan \\ e-mail: *mkm7879@hu.edu.jo, **osamelhem@hu.edu.jo
}

\begin{abstract}
The study attempted to characterize students' conceptions of learning and approaches to learning and revealing the correlation between the students' concepts and approaches to learning. The researchers used qualitative content analysis and a descriptive approach. The study population comprised 90 male and female students of the Faculty of Educational Science at a university in Jordan, during the 2019/2020 academic year. The quantitative concepts were dominating among students $(87.77 \%)$, especially the concept of learning as a knowledge increase (33.33\%). On the other hand, the qualitative concepts of learning were low (12.22\%), especially on the person change (2.22\%). In addition, there was an emergence of a new concept of learning outside the traditional concepts, namely learning as exam preparation. The results showed that the deep approach to learning was low, and the surface approach to learning was high. The results further showed a correlation between the quantitative concepts of learning and the surface approach to learning, as well as a correlation between the qualitative concepts of learning the deep approach to learning. Hence, the general conclusion implies that if teachers are to place learners at the heart of the learning process, they must be aware of the concepts of learning and learning approaches of the students.
\end{abstract}

Keywords: approaches to learning, concepts of learning, university students, surface approach to learning, deep approach to learning

\section{INTRODUCTION}

Learning is a complicated process that cannot be easily defined. Perhaps the following definition is the most famous: "learning is a semi-constant change process in the behavior or the behavioral power, resulting from an experience" (Wallace, 2009: 29). However, this definition does not consider the various personal, social, and emotional aspects used in learning (Entwistle \& Peterson, 2004). For instance, an opinion poll conducted by Klatter, Lodewijks, \& Aarnoustes (2001) showed that individuals have different ideas about learning. Some people refer to it as learning implications, others as learning necessities; still others refer to it as learning objectives. These different and close learning dimensions lead to the idea that learning is a multidimensional structure (Peterson, Brown, \& Irving, 2010). Such a multidimensional property allows students to hold different learning concepts.

Learning concepts are defined as the learner's thoughts and beliefs about learning (Klan, Abdou, Kettumen \& Gregory, 2010; Lai \& Chan, 2005). Since the learning concepts are formulated through the learner's cultural values (Hong \& Salili, 2000), six basic learning concepts were defined among different cultures and societies, such as the USA, Australia, and Malaysia (Purdie \& Hattie, 2002); China (Lai \& Chan, 2005), and New Zealand (Peterson et al., 2010). The concepts are learning as information acquisition, learning as information retrieval and use, learning as a duty, learning as a personal change, learning as a process unrelated to time or space, and learning as social development.

Researchers divided the learning concepts into a hierarchical sequence, such as surface or quantitative, versus deep or quality learning concepts (Boulton-Lewis, Marton, Lewis, \& Wilss, 2000), which include the learning quantitative concepts to obtain and reconstruct the information. Meanwhile, qualitative concepts include understanding the meaning and personal change (Purdie \& Hattie, 2002). Yang, Leung, \& Zhang (2019) believe in the existence of two main learning concepts: quantitative and qualitative concepts.

The quantitative learning concept assumes that learning is a content collection process; thus, the greater the individual's knowledge, the more his/her proficiency is. The qualitative 
concept of learning assumes that learning is the individual's interpretation and integration of the new knowledge presented to him/her, along with what he/she already knows.

Marton, Dall'Alba, \& Beaty (1993) proposed a model about the learning concept, which included six concepts. The first three concepts emphasize the quantitative learning concept. 1) Learning is an increase in the individual's knowledge by acquiring new knowledge; 2) Learning is the individual's retention of information in his/her memory and retrieving them later; 3) Learning is the individual's use of the information he/she already acquired. The remaining three concepts focus on the qualitative learning concept; 4) Learning is an increase in the individual's understanding of things; 5) Learning makes the individual look at things differently; and 6) Learning changes the individual as a person. Every subsequent view is more developed and deeper than the preceding. For example, the third concept is more developed and deeper than both the first and second concepts and comes after them (Alamdarloo, Moradi, \& Dehshiri, 2013; Sadi \& Dagyar, 2015).

In the same direction, Edmunds \& Richardson (2009) assumed that the single learner can hold contradicting concepts on both the qualitative and quantitative learning at the same time. Dahlin \& Watkins (2000) indicated that students showed sophisticated concepts of learning. They used repetition and learning by heart to improve their understanding of the subject. They also indicated, in the same study, that previous studies stated that a large portion of the students and teachers in the near east countries suggested that remembering and understanding work side by side to produce higher quality learning outcomes of better quality. Marouchou (2012) concluded that several students attempted to learn the subject by heart in their memories, and, at the same time, showed a good understanding of that subject.

As for the approaches to learning, the differences among the students in the learning outcomes were explained through reference to the differences between them in terms of their processing the learning tasks. Still, admitting that the students' motive to perform the learning task is responsible for the differences among them in processing these tasks. Currently, many of the educational researchers show a tendency to interpret the specific differences in the students' learning outcomes using two factors: student's motive to start the learning task and the strategy used to carry out this task (Allan, 2003; Duff \& McKinstry, 2007; Lindblom-Ylänne, Parpala, \& Postareff, 2019; Núñez, Paiva, Lourenço, Cerezo \& Valle, 2013).

Depending on the previous and current explanations, the term "approaches to learning" was used to describe the difference between the students in their dealings with the learning tasks. Further, the distinction was made between two different types of approaches to learning, i.e. surface and deep approaches (Monroy \& Gonzalez-Geraldo, 2018). Also, Monroy \& Pina (2014) defined the approaches to learning as the specific differences among the students in their learning process. These differences reflect the nature of the relationship between the student, the learning task and the learning context. Abhayawansa \& Fonseca (2010) distinguished between two major types of approaches to learning: the deep approach with its strategies and motives, and the surface approach with its strategies and motives too, which distinguishes it totally from the deep approach.

Approaches to learning are defined through many factors, such as the student's traits, the environment where the student learns, and his/her learning outcomes. Therefore, it is possible to transfer the student's approaches to learning from the surface to deep using convenient strategies (Richardson, 2010; Tsai, Chai, Hong \& Koh, 2017).

Approaches to learning are not considered personal characteristics, as talking about a deep learning learner and surface learning learner is unacceptable. On the other hand, the different types (surface and deep) of the approaches to learning are not deemed developmental thresholds through which learners enter. A single learner can adopt a deep approach in a certain context and a surface approach in another because adopting one approach rather than the other relies on the learning context and his/her interpretation of this context (Valadas, 2013; Yang et al., 2019).

A deep approach to learning emerges with the student from his/her perceived needs, such as his/her internal interest to engage in the learning task in a manner that fits the task. Furthermore, the deep approach to learning appears from the 
student's focus on the meaning contained in the learning material and its main ideas; avoiding the conceptually unsupported details; his/her attempt to link the concepts presented to him/her for the first time with his/her previous experience; the practice of the critical thinking; and, carrying out high-level mental processes. Accordingly, a deep approach to learning requires the student to possess a sufficient base of previous knowledge on the subject presented to him/her (Tsai et al., 2017).

Deep approaches to knowledge have special strategies, such as the student's endeavor to the meaning contained in the academic subject and using proofs to reach understanding. In the deep approach, the student's learning outcomes are most probably suitable to the learning task he/she carries out, and are of high quality as compared to the learning outcomes in the surface approach (Guner \& Riza, 2008; Monroy \& Pina, 2014; Núñez et al., 2013; Richardson, 2011). Meanwhile, the student's approach to learning is related to low-level learning activities at the cognitive level, at the time when achieving the learning task requires high-level learning activities and efforts the student does not want to spend properly. Moreover, the student's surface approach is related to his/her rote memorizing of elected parts of the content rather than understanding them; focus on isolated facts; and, dealing in elements included in the content as elements separated from each other. The surface approach is also connected to the student's inability to distinguish between the new ideas presented to him/her from the previous knowledge he/she has; considering the learning tasks as being imposed on him/her from outside; and, the lack of the learning process of the student's meditation in the objective of these tasks and the strategies used to achieve them. Most often, for the student, learning is a source of negative feelings, such as anxiety and boredom (Abhayawansa \& Fonseca, 2010; Biggs \& Tang, 2007; Richardson, 2011). The student has specific motives to adopt the surface approach to learning, such as student's fear of failure and endeavor to achieve objectives other than learning. Furthermore, the student has special strategies for the surface approach to learning, such as concentration on learning by heart rather than understanding, and restricting his/her concern to what is required by the curriculum (Biggs \& Tang, 2007; Duarte, 2007; Guner \& Riza, 2008; Tsai et al., 2017).

Several factors can contribute to encouraging the student to adopt a surface approach to learning. For instance, student's priorities that are unrelated to learning, which dominates his/her learning-related priorities; student's evaluation processes that focus on the examinations; the curriculum that is characterized by a lack of compatibility between the volume of the course subject and time allocated to cover it; and the excessive use of the learning methods that are based on the principle that learning is a knowledge transference process to the student. Also, the student's misunderstanding of the learning requirements is another factor, such as remembering the facts is quite sufficient to "reap" new learning outcomes (Biggs \& Tang, 2007; Monroy \& Pina, 2014).

There is a difference between the student's description of his/her concept of learning and the description of his/her approach to learning. When the student describes his/her approach to learning, he/she will be engaged in a thinking and reflection process in responding to the learning task, with his/her focus is on the matter he/she learns (Vettori, Vezzani, Bigozzi, \& Pinto, 2018). But, when the student describes his/her concept of learning, he/she is engaged in a thinking and reflection process in the learning itself, with his/her focus is on learning its general meaning (Boulton-Lewis et al., 2000).

Many studies support the argument that students' learning Approaches are related to their Concepts of learning and that learning Approaches are related to the quality of learning outcomes (Suyitno, Pratiwi, \& Martutik, 2019). Other studies found it is possible to use learning concepts to define students' learning Approaches (Mørk, Magne, Carstensen, Stigen, Åsli, Gramstad, ... \& Bonsaksen 2020; Suyitno et al., 2019; Tuononen, Parpala, \& Lindblom-Ylänne, 2019).

However, several inconsistent findings have been identified in previous studies. For example, Li, Liang, \& Tsai (2013) found that students' lower-level learning concepts, 'learning as memorization', could positively predict deep learning motivation, whereas higher-level learning concepts were positively correlated with surface motivation in learning. The researchers have argued that this kind of 
discrepancy may be the result of differences in contexts and subject areas, in other words, since students perform differently in different areas of learning and educational contexts, the relationship between students' Concepts of learning and learning Approaches may also be different.

In this concern, Yang et al. (2019) conducted a study aimed at investigating the students' concepts of learning and their approaches to learning. The results of the analysis indicated that the students tend to possess highlevel concepts on learning rather than low-level, and deep approaches to learning with a surface motive somewhat mixed with a deep motive. The results of the correlation analysis confirmed the existence of a relationship between the students' concepts and their approaches to learning.

The study of Monroy \& González-Geraldo (2018) aimed at identifying the affinity between the quantitative and qualitative responses when measuring their concepts and approaches to learning. In general, the quantitative and qualitative data did not support each other, as the responses showed a clear dominance of a deep, non-surface approach to learning. Meanwhile, the qualitative responses reflect a tendency towards low-order learning concepts.

The results of the study of Tsai et al. (2017) revealed that students who have quantitative concepts tend to the surface approaches for knowledge building. Meanwhile, students with qualitative view tend to follow deep approaches to learning. The results further showed that students with qualitative concepts were more achieving than those with quantitative approaches to learning. Abhayawansa \& Fonseca (2010) explored the learning concepts and approaches to learning of a group of Sri Lankan students in an Australian university using the semi-structured interviews for data collection. The results showed that the interviewed students have low-level concepts of learning, and the surface learning properties appeared with them.

Guner \& Riza (2008) conducted a study aimed at an attempt to determine the university students' approaches to learning. The results showed that there were deep approaches to learning with the students. Duarte (2007) made a study aimed at identifying university students' concepts of learning and their approaches to learning. The study showed three types of approaches to learning: deep, surface, and achievement. The study emphasized the existence of most of the learning concepts, which were discovered previously in other research works. Such as, deeming learning as a remembering process and seeing learning as understanding. The results also showed the emergence of a new view of learning, namely seeing learning as a reflection and application.

If the educators were willing to find ways to improve the students' learning experiences and outcomes, they first have to understand how students learn, and how their concept of learning and learning environments within which they learn affect their approaches to learning. Relying on this rule, this study is made as an attempt to understand the way students of the HU University in Jordan learn, and to understand the relationships among these students' concepts on learning and their approaches to learning, to promote the quality of their learning outcomes.

The researcher, through his/her experience in education, noted that a large number of the university students focus, in a major portion of their learning process, on the strategy of like-rote learning by heart of the subject contents rather than focusing on understanding them, which negatively affects their learning outcomes. The researcher also noted that many of these students do not remember much of what they learned, do not understand much of what the retrieved, and do not use what they previously learned in their daily life. The researcher expects that this problem with the students will have a close relationship with their learning concept and approaches to learning. Based on the significance of this issue, this study attempts to reveal the students' concepts, their approaches to learning and the relationships between them.

Identifying the student's concepts and their approaches to learning are major factors to take meaningful educational precautions for the future. Today students are tomorrow teachers and policymakers in the education area. In this context, it is necessary to identify the students' concepts toward learning. Therefore, this study aims at measuring the level of each of the quantitative and qualitative concepts of learning with the HU University students during the academic year 2019/2020. It also aims at measuring the students' deep and surface approaches to learning and revealing the 
correlation between the students' concepts and their approaches to learning.

\section{METHODS}

The researcher employed the qualitative content analysis and the descriptive approach. The study comprised 90 students, of the Faculty of Educational Science at a university in Jordan during the academic year 2019/2020, 20 of them are males and 70 are females. All students who participated in the study took courses related to learning such as evaluation of student learning, learning theories, educational psychology. The students are undertaking this major to become teachers in the basic stage schools. The age mean is 21.9 years, and the range is $19-24$.

To identify the students' concepts of learning, each student was asked to answer the following open question: "What is learning? Please explain?" Students were given about 15 minutes to write the meaning of learning. To identify the students' approaches to learning, two questionnaires were constructed by reference to the educational literature, particularly: (Abhayawansa \& Fonseca, 2010; Allan, 2003; Duarte, 2007; Tsai et al., 2017; Valadas, 2013; Yang et al., 2019). The questionnaire consisted of two domains, the deep and surface method, and every domain included two sub-factors, motivation and strategy. Subsequently, the questionnaire consisted of four sub-factors. Here below is a description of each of the four factors (from 6 to 9 elements for every scale, with a total of 29 elements).

(a) Deep motive: learning is supported through the students' internal interests and motives, such as I work hard in the study because I find it very entertaining.

(b) Deep strategy: Deep strategy: Learning is done with more effective strategies. such as I make a lot of effort to understand the meaning of the content I am studying.

(c) Surface motive: learning is moved by external motives, such as I want to improve my performance in learning to be able to please my parents.

(d) Surface strategy: learning is made by using rote-like strategies, such as I think the best way to pass exams is to remember the answers or procedures for potential questions.
For the responses of the questionnaire items, a Likert five-point scale was adopted: Always (5), often (4), sometimes (3), rarely (2), and never (1). To ensure the validity of the instrument, it was presented to (14) reviewers and amendments were made based on their suggestions. Besides, to ensure its reliability, the researcher distributed it on an exploratory sample consisted of 40 students from inside and outside the study population. Then the researcher carried out the exploratory factorial analysis of the collected data. Based on the analysis process, 4 items of the questionnaire were deleted as they got weak results, bringing the questionnaire to include 25 items only. Cronbach Alfa of the internal consistency of the questionnaire was calculated, as shown in Table 1 that the questionnaire enjoys a sufficient reliability value.

\section{Table 1. Internal Consistency Coefficients}

\begin{tabular}{lc}
\hline Domain and Dimension & $\begin{array}{c}\text { Cronbach Alfa } \\
\text { Coefficient }\end{array}$ \\
\hline Deep approach to learning domain & .853 \\
*Deep motive to learning dimension & .812 \\
*Deep learning strategy dimension & .798 \\
Surface approach to learning domain & .827 \\
*Surface learning motive dimension & .805 \\
*Surface learning strategy dimension & .784 \\
\hline
\end{tabular}

As for the first question, in the first stage, the Students $(N=90)$ were asked to write what they believed that meant learning. For the data analysis, the researchers employed the qualitative content analysis (Yildirim \& Simsek, 2005). The summary of the analysis process in this study was as follows: (1) The answers of all the responses were read independently by the researchers to determine all the differences in the learning concept and formation of categories; (2) Following the first reading, the researchers classified the interpreted concepts and formed the start groups; (3) The researchers discussed the groups and agreed on the start groups; (4) Following the discussion, the researchers read the responses anew to establish the main categories; (5) The groups that every researcher determined were discussed until the researchers agreed on them; (6) The reading and repeated discussion continued until the researchers reached a $100 \%$ agreement rate on the categories; (7) The categories were grouped into two categories, namely: the quantitative and qualitative concepts of learning. 
Two researchers analyzed student answers and the agreement factor was calculated between them with reliance on Cohen (1960) (Cohen's kappa). The agreement factor was .94, which is an excellent agreement rate according to Cicchetti (1994), Many studies showed that this type of data analysis techniques provides reliable results (Abhayawansa \& Fonseca, 2010; Khan, Abdou, Kettunen, \& Gregory, 2019; Monroy \& González-Geraldo, 2018; Owusu-Agyeman \& Fourie-Malherbe, 2018).

As for the second question, the researchers applied the descriptive method, as well as the means $(M)$ and standard deviations $(S D)$. Means were used to determining the level of both the students' deep and surface approaches to learning. The approach was judged in the light of the mean as follows: $1.8>M \geq 1=$ very low, $2.6>M \geq 1.8=$ low, $3.4>M \geq 2.6$
$=$ moderate, $4.2>M \geq 3.4=$ high, and $5>M \geq 4.2=$ very high

To answer the second question, the PointBiserial test was applied to reveal the correlation between the students' views and approaches to learning.

\section{FINDINGS AND DISCUSSION \\ Findings \\ Student's Concepts of Learning}

The students' concepts of learning were grouped into six categories, with a dominance of the quantitative categories (87.77\%), particularly, considering learning as an increase of knowledge. Meanwhile, the qualitative concepts to learning were low with the participants $(12.22 \%)$, particularly seeing learning as a change of the person $(2.22 \%)$, as provided in the Table 2 .

Table 2. Classification of the Students' Concepts on Learning

\begin{tabular}{llccc}
\hline $\begin{array}{l}\text { Type of the } \\
\text { Concept }\end{array}$ & Outlook for Learning & No & \% & $\begin{array}{c}\text { \% of the } \\
\text { Concept Type }\end{array}$ \\
\hline Quantitative & 1) Increasing the knowledge & 30 & $33.33 \%$ & $87.77 \%$ \\
& 2) Like-rote, learning by heart & 18 & $20.00 \%$ & \\
& 22 & $24.44 \%$ & \\
3) Acquiring facts and procedures & 9 & $10.00 \%$ & \\
Qualitative & 5 & $5.56 \%$ & $12.22 \%$ \\
& 4) Preparing for the exams & 4 & $4.44 \%$ & \\
& 5) Meaning abstraction & 2 & $2.22 \%$ & \\
\hline
\end{tabular}

First Concept: increase in knowledge: The students, in this category, see learning concept as an increase in knowledge (33.33\%). For instance, "Learning is an accumulative increase in the daily individual's knowledge (Student 45)."'In my view, learning is gathering information about a certain subject, and an increase in the individual's knowledge in that subject" (Student 3) and "It is a defined knowledge gathering process about a certain theory or subject" (Student 15).

Second Concept: like-rote (learning by heart): In this category, the Students see the learning concept as a like-rote $(20 \%)$. For example, "In my view, learning is achieved by 'storing the information' from the visual and written sources in the human brain" (Student 20) and "Learning is gathering and rereading information, like-rote, and repetition when necessary; to succeed in a certain subject or pass the examination" (Student 33).
Third Concept: acquiring facts and procedures: Students of this category concentrated on the learning concept as acquiring facts and procedures (24.44\%). For example, "Learning is knowledge acquiring and using such knowledge to solve problems faced in daily life" (Student 81) and "Learning is gaining new knowledge and implementing such knowledge, when needed, under different circumstances" (Student 15).

Fourth Concept: preparing for the examinations: Here, students of this category concentrated on the learning concept as a preparation process for the examinations and obtaining high scores $(10 \%)$. For instance, "For me, learning is to gain higher grades in the examinations" (Student 15) and "In my opinion, learning is to pass all my examinations with satisfying grades" (Student 29).

Fifth Concept: meaning abstraction: In this category, students emphasized the learning 
concept as the abstraction of the meaning $(5.56 \%)$. For example, "Learning is obtaining information about unknown phenomena, and discovering the right answers about the phenomenon. Anybody can develop a solution to a certain problem through learning" (Student 76). And, "in my view, "Learning is the attempt of the individual to understand the meaning of nature, ask about the real-world events, and add meaning to the events around him/her through his/her current knowledge" (Student 61).

Sixth Concept: interpretive process to understand the reality: Students of this category concentrated on the learning concept as an interpretive process that aims to understand the reality $(4.44 \%)$. For instance, "Learning is a process that lasts lifelong, during which we add new knowledge to our current knowledge and reconstruct our concepts. In this way, we develop new skills and new understanding" (Student 83).
Seventh Concept: individual's change: Students of this category concentrated on the learning concept of the individual's change $(2.22 \%)$. For example, "People learn new things every day. In my view, learning is the change and development in the individual's personality, experience, and perspective in life" (Student 47).

\section{Students' Approaches to Learning}

The researchers obtained the mean of the students' responses to the approaches to learning questionnaire in both the learning motive and learning strategy. The results showed that the deep learning motive and deep learning strategy with the students were low, as $M s$ were $(2.46,2.34)$, respectively. The deep approach to learning was medium (2.40), and both the surface learning motive and surface learning strategy were high $(M s=2.75,3.86)$, respectively. Finally, the surface approach to learning was high $(M=$ 3.80), as shown in Table 3.

Table 3. $M s$ and $S D$ s of the Approaches to Learning

\begin{tabular}{lcclcc}
\hline Domain and Dimension & $\boldsymbol{M}$ & $\boldsymbol{S D}$ & Domain and Dimension & $\boldsymbol{M}$ & $\boldsymbol{S D}$ \\
\hline Deep learning motive & 2.46 & .17 & Surface learning motive & 3.75 & .14 \\
Deep learning strategies & 2.34 & .20 & Surface learning motive & 3.86 & .16 \\
The domain of the deep & 2.40 & .19 & $\begin{array}{l}\text { The domain of the surface } \\
\text { approach to learning }\end{array}$ & 3.80 & .15 \\
approach to learning & & & &
\end{tabular}

\section{The Correlation between the Students' Concepts of Learning and Their Approaches to Learning}

To reveal the correlation between the students' concepts of learning and their approaches to learning, the Point-Biserial correlation coefficient was calculated. The results showed a statistically significant correlation between three categories of the quantitative concepts to learning: (knowledge increase, likerote, and acquiring facts and procedures), and the two dimensions of the surface approach to learning: (surface motive and surface strategy). The researchers determined the correlations (weak or even negative) between these categories and the two dimensions of the deep approach to learning (deep motive and deep strategy).

The results also showed a statistically significant correlation between three categories of the qualitative concepts to learning: (meaning abstraction, interpretive process to understand the reality and person change), and the two dimensions of the deep approach to learning: (deep motive and deep strategy. The correlations were defined (weak or even negative) between these categories and the two dimensions of the surface approach to learning (surface motive and surface strategy), as shown in Table 4.

Table 4. Correlation between the Students' Views to Learning and Their Approaches to Learning

\begin{tabular}{lllcc}
\hline Scale & $\begin{array}{l}\text { Surface } \\
\text { Motive }\end{array}$ & $\begin{array}{l}\text { Surface } \\
\text { Strategy }\end{array}$ & $\begin{array}{c}\text { Deep } \\
\text { Motive }\end{array}$ & $\begin{array}{l}\text { Deep } \\
\text { Strategy }\end{array}$ \\
\hline 1) Knowledge increase & $* * .886$ & $* * .886$ & -.201 & -.013 \\
2) like-rote, learning by heart & $* * .77$ & $* * .65$ & .006 & $* *-.737$ \\
3) Acquiring facts and procedures & $* * .652$ & $* * .687$ & .174 & .167 \\
4) Preparing to the examinations & $* * . .279$ & $* * .276$ & .1498 & $* *-.272$ \\
5) Meaning abstraction & $* *-.396$ &. .002 & $* .261$ & $* * .322$ \\
6) Interpretive process to understand the reality & -.014 & $* *-.383$ & $* * .374$ & $* * .396$ \\
7) Person change & -.267 & .044 & $* * .442$ & $* * .508$ \\
\hline
\end{tabular}

Note: $* p<.05, * * p<.01$ 


\section{Discussion}

The results related to the students' concepts to learning showed that the quantitative concept is dominant with the students, particularly understanding learning as a knowledge increase. On the other hand, the qualitative concepts to learning were low with the study participants, particularly the view of learning as a person change. The results indicated that the students' concepts of learning cover all the differences in the six categories determined by Marton et al. (1993). Also, a new concept to learning appeared outside these six concepts, namely learning as preparing for the examinations. The participants focused, to a wide extent, on the view of learning as a knowledge increase and acquiring facts and procedures.

The results showed that the participants do not have the same concepts to learning, as their views about learning as a knowledge increase and acquiring facts and procedures are undesired. The results of this study confirm the results of previous studies conducted on the students' views on learning and approach to learning (Boulton-Lewis et al., 2000; OwusuAgyeman \& Fourie-Malherbe, 2018; Tsai, 2004).

The results further showed that a high percentage of the participants held strong quantitative concepts to learning. Undoubtedly, these students were exposed, in a certain stage of their education, to teaching methods and evaluation dealt with their learning processes as mere knowledge transference processes from their teachers to them. It is also possible that these methods contributed to the generation of a strong quantitative view to learning with these students.

As for the statistics of the students' approaches to learning, the results showed a high level of surface approach and low level of a deep approach to learning. The results showed that surface approach students are more likely to wait until the last minute to study for exams, often relying on memorization strategies. Many of these students admitted to procrastinating learning tasks in most of their classrooms. There was a variation in the emphasis placed by these students on the importance of applying knowledge outside of the classroom or relating it to other knowledge and experiences.

Integrating prior knowledge and applying the information to external situations was not a goal for all surface approach students. While some students spoke of reflecting on and applying what they had learned, others did not think of it as a contribution to their learning. Even for those students who have demonstrated a tendency to place some importance on applying knowledge outside of the classroom or relating it to other knowledge and experiences, this higher-level concept of learning did not correlate with the actual learning practices they described which emphasized immediate recall of knowledge based on memorization.

Most probably, these students were previously exposed to poor teaching and evaluation, which perhaps contributed, in part, to the generation of surface approaches to learning with them. This result is in line with the view of Valadas (2013), who believes that students' approaches to learning could tell us many things about the quality of the environment that nurtures the students. This is because the students' approaches to learning tend, to a certain extent, to acclimatize with the expected requirements in their educational environment. The results of this study somewhat agree with those of Ramburuth \& McCormick (2001), which showed that the students who participated in the study demonstrated a significantly greater degree of the use of surface approach motive and surface approach strategy.

Here, we must not forget the role of the curriculum and its influences in the students' approaches to learning, because the curriculum is in the heart of the learning and teaching processes. In our current study, the excessive volume of the contents of some schoolbooks may form a great time-pressure on the participants and their teachers. This pressure reflected negatively on the participants' approaches to learning through its negative influence in each of the tools employed to evaluate the presented material, the depth of the students' reflection on the material, and the amount of time provided to the students to meditate and think in the study affairs.

While students with a deep learning approach focus their perception of what learning entails around understanding content, rather than just memorizing it, this focus on understanding has been supported by learning strategies that incorporate prior learning experiences, relate them to the world around them, and 
apply knowledge to other situations. Students also established the ability to discuss and explain concepts with someone as an essential characteristic of learning.

Unlike surface approach students, students in this group did not believe that the focus of their learning should be on trying to discover what the teacher thinks is important as a way to predict test questions. Instead, they looked to comprehension as the primary goal of learning. This finding was supported by research that revealed that higher concepts of learning promoted a deeper approach to learning (Monroy \& González-Geraldo, 2018; Shen, Lee, Tsai \& Chang, 2016; Purdie \& Hattie, 2002).

These students realized that learning was not just about getting a good grade in the classroom but taking that learning outside of the classroom. This focus on comprehension is supported by learning strategies that integrate learning experiences with the world around them and apply knowledge to other situations.

The researchers believe that approaches to learning can be cultivated from the learning tasks required in the course. Instructors can help students become familiar with specific learning strategies through coaching and practice in the classroom and assign learning tasks that require students to implement them. Additionally, special interest can be incorporated into the learning expectations relayed to the students throughout the course. A high level of understanding and application of what has been learned should be the focus of some parts of the exams that will help students develop deep approaches to learning.

The third main purpose of the study is to explore the relationships between students' concepts of learning and their approaches to learning. In general, the results of the study show that two of the students' lower-level concepts of "increasing knowledge and like-rote, learning by heart " are strongly positively correlated with students' surface approaches to learning, and they are negatively correlated with deep approaches to learning, The results in this study indicate that strong concepts of "increasing knowledge and like-rote, learning by heart “ tend to lead students to use more rote learning approaches in learning, which are important for exam success.

This result does not agree with the results of some previous studies that found that the concept of learning "exam preparation" is the only one that had positively correlated with students' surface approaches to learning (Chiou, Lee, \& Tsai, 2013; Lee, Johanson, \& Tsai, 2008). As well as the study of Li et al. (2013), which revealed that learning through memorization can positively predict a deep motivation to learn, while a higher level of learning was positively correlated with students' surface approaches to learning.

Moreover, the results showed a statistically significant correlation between three groups of the quantitative concept to learning (knowledge increase, like-rote, and acquiring facts and procedures), on the one hand, and the two dimensions of the surface approach to learning (surface motive and surface strategy), this may be due to the influence of examination pressure, In Jordan, students need to take examinations frequently. They may not have a deep motive in learning due to the influences or pressure that come with the context in which the learning takes place which is similar to findings in previous studies (Abhayawansa \& Fonseca, 2010; Duarte, 2007; Chiou, Lee \& Tsai, 2013). For example, Chiou et al. (2013) found that "Acquiring facts and procedures" in Taiwanese students' conception of learning positively predicted students' surface motive.

On the other, There was also a statistically significant correlation between three categories of the qualitative concept to learning (meaning abstraction, interpretive process aiming at understanding the reality, and personal change), and the two dimensions of the deep approach to learning (deep motive and deep strategy), which is similar to findings in previous studies (Edmunds \& Richardson, 2009; Lee et al., 2008; Umapathy, Ritzhaupt, \& Xu, 2020).

Possibly, one of the reasons for the existence of this correlation may be ascribed to the beliefs of the study participants about learning, which was brought with them from their environments. Probably, these beliefs practiced a stronger influence on their approaches to learning than that of the learning context. This conclusion on the relationship between the students' concept and approaches to learning is in line with the study of (Entwistle \& Peterson, 2004; Richardson, 2011; Richardson, 2010; Valadas, 2013), which indicated that the students who 
showed the existence of a qualitative concept to learning held deep approaches to learning.

These results are consistent with findings in previous studies that students with low-level concepts of learning are more likely to use surface approaches to learning, while students with higher-level learning concepts tend to adopt deep approaches to learning, For example, Chiou et al. (2013) Found that students' higher-level learning concepts such as "seeing problems in a new way" are more likely to correlate positively with their deep approaches to learning, while lower-level learning concepts such as "Preparing to the examinations" are more related to their surface approaches to learning.

The researchers believe that to help students to make the connection between their concepts of learning and appropriate strategies towards that learning, there must be changes not only in the students' approaches for intended learning but also in the teaching strategies of their instructors. Instructors should carefully study the context of their courses, especially student characteristics. This information will assist teachers in designing curriculum, using teaching methods, designing learning tasks, and choosing assessment methods to measure the learning content and skills they wish students to learn.

Besides direct teaching, other teaching strategies should be used to encourage students to become more active in the classroom, the teaching methods should focus more on facilitating student learning. Instructors may be able to manipulate student approaches to learning by providing indications or examples of how students are dealing with learning on specific tasks. For example, the instructor might say, "The exam will consist of essay questions that require you to apply the material to actual situations." These cues may be powerful enough to override students' surface approaches to learning.

The connection that students make between their idea of what learning is and how they set out to achieve that learning is something that may continue unchanged without instructor intervention. Therefore, increasing instructors' pedagogical content knowledge is a critical step that must be considered. This task can be achieved by providing instructors with contentspecific professional development regarding learning objectives, teaching strategies, and assessment methods that encourage student learning.

\section{CONCLUSIONS}

The study shows the quantitative concepts were dominating among the students, especially, the concept of learning as a knowledge increase and the qualitative concepts to learning were low, especially, the person change. In addition to the emergence of a new concept of learning outside the traditional concepts, which is learning as exam preparation. The results showed that the deep approach to learning was low, and the surface approach to learning was high. The results further showed a statistically significant correlation between the quantitative concepts to learning and the surface approach to learning, as well as a statistically significant correlation between the qualitative concepts to learning the deep approach to learning.

As for the practical effects, firstly, the study results indicate that, in practice, teachers can carry out attempts to enhance the students' qualitative concepts to learning, such as learning is an interpretive process aiming at understanding the reality, and learning is the person change. Secondly, to achieve a better understanding of the relationship of the concepts to learning and approaches to learning, there is a need for more studies in other cultural and social contexts. Third, the study did not explore a process to develop or change the students' concepts to learning. However, future studies may look into designing a longitude study to realize a developmental process on the students' concepts and approaches to learning.

The following factors limited the results of this study. The study was conducted on certain aspects of the human learning topic, namely the students' views of learning and their approaches to learning. The study was confined to a limited number of students at the HU University in Jordan. Therefore, the results could be generalized to the university community only. In addition, the current study employed the interview to explore the students' views as well as the questionnaire to reveal their approaches to learning. Finally, future studies in this issue can use other research methods to realize a deeper and fuller understanding of the students' views and approaches to learning. 


\section{ACKNOWLEDGEMENT}

We are grateful to the help of Faculty members and students at the HU University.

\section{REFERENCES}

Abhayawansa, S., \& Fonseca. L. (2010). Conceptions of learning and approaches to learning? A phenomenographic study of a group of overseas accounting students from Sri Lanka. Accounting Education, 19(5), 527-550. https://doi.org /10.1080/09639284.2010.502651.

Alamdarloo, G., Moradi, S. \& Dehshiri, G. (2013). The relationship between students' conceptions of learning and their academic achievement. Psychology, 4(1), 44-49. https://doi.org/10.4236/ psych.2013.41006.

Allan, B. (2003). Approaches to learning and academic achievement of Filipino students. The Journal of Genetic Psychology, 164(1), 101-114. https://doi. org/10.1080/00221320309597506.

Biggs, J. \& Tang, C. (2007). Teaching for quality learning at the university: what the student does? ( $3^{\text {rd }}$ ed). New York, NY: Open University Press.

Boulton-Lewis, G., Marton, F., Lewis, D., \& Wilss, L. (2000). Learning in formal and informal contexts: Conceptions and strategies of Aboriginal and Torres Strait Islander university students. Learning and Instruction, 10(5), 393-444. https://doi. org/10.1016/S0959-4752(00)00005-0.

Chiou, G., Lee, M., \& Tsai, C. (2013). High school students' approaches to learning physics with relationship to epistemic views on physics and conceptions of learning physics. Research in Science and Technological Education, 31(1), 1-15. https://doi.org/10.1080/02635143.2013.7 94134.

Cicchetti, D. (1994). Guidelines, criteria, and rules of thumb for evaluating normed and standardized assessment instruments in psychology. Psychological Assessment, 6(4), 284-290.
Cohen, J. (1960) A coefficient of agreement for nominal scales. Educational and Psychological Measurement, 20, 37-46. https://doi. org/10.1177/001316446002000104.

Dahlin, B., \& Watkins, D. (2000). The role of repetition in the processes of memorising and understanding: A comparison of the reviews of German and Chinese secondary school students in Hong Kong. British Journal of Educational Psychology, 70(1), 65-84. https://doi. org/10.1348/000709900157976.

Duarte, A. (2007). Conceptions of learning and approaches to learning in Portuguese students. Higher Education, 54(6), 781794. https://doi.org/10.1007/s10734006-9023-7.

Duff, A., \& McKinstry, S. (2007). Students' approaches to learning. Issues in Accounting Education, 22(2), 183214. https://doi.org/10.2308/ iace.2007.22.2.183.

Edmunds, R., \& Richardson, J. (2009). Conceptions of learning approaches to studying and personal development in UK Higher Education. British Journal of Educational Psychology, 79(2), 295-309. https://doi. org/10.1348/000709908X368866.

Entwistle, N. J., \& Peterson, E. R. (2004). Conceptions of learning and knowledge in higher education: Relationships with study behaviour and influences of learning environments. International Journal of Educational Research, 41(2004), 407-428. https://doi:10.1016/j.ijer.2005.08.009.

Güner, T. D., \& Riza, A. A. (2008). Examining learning approaches of science student teachers according to the class level and gender. US-China Education Review, $5(12), 54-59$

Hong, Y.-Y., \& Salili, F. (2000). Challenges ahead for research on Chinese students' learning motivation in the new millennium. Journal of Psychology in Chinese Societies, 1(2), $1-12$ 
Khan, M., Abdou, B., Kettunen, J., \& Gregory, S. (2019). A phenomenographic research study of students' conceptions of mobile learning: An example from higher education. SAGE Open, 9(3), 1-17. https:// doi.org/10.1177/2158244019861457.

Klatter, E. B., Lodewijks, H. G. L. C., \& Aarnouste, C. A. J. (2001). Learning conceptions of young students in the final year of primary education. Learning and Instruction, 11(6), 485-516. https://doi. org/10.1016/S0959-4752(01)00002-0.

Lai, P. Y. M., \& Chan, K. W. (2005, 28 November-2 December). A structural model of conceptions of learning, achievement motivation and learning strategies of Hong Kong teacher education students. Paper presented at Australian Association of Research in Education Parramatta Conference, Sydney. https:// www.aare.edu.au/data/publications/2005/ lai05464.pdf.

Lee, M.-H., Johanson, R., \& Tsai, C.-C. (2008). Exploring Taiwanese high school students' conceptions of and approaches to learning science through a structural equation modeling analysis. Science Education, 92(2), 191-220. https://doi.org/10.1002/ sce. 20245 .

Li, W.-T., Liang, J.-C., \& Tsai, C.-C. (2013). Relational analysis of college chemistrymajor students' conceptions of and approaches to learning chemistry. Chemistry Education Research and Practice, 14(4), 555-565. https://doi. org/10.1039/C3RP00034F.

Lindblom-Ylänne, S., Parpala, A., \& Postareff, L. (2019). What constitutes the surface approach to learning in the light of new empirical evidence? Studies in Higher Education, 44(12), 2183-2195. https:// doi.org/10.1080/03075079.2018.148226 7.

Marouchou, D. V. (2012). Can students' concept of learning influence their learning outcomes? Higher Learning Research Communications, 2(2), 18-33. https://doi. org/10.18870/hlrc.v2i2.23.
Marton, F., Dall' Alba, G., \& Beaty, E. (1993). Conceptions of learning. International Journal of Educational Research, 19(3), 277-300.

Monroy, F., \& González-Geraldo, J. (2018). Measuring learning: discrepancies between conceptions of and approaches to learning. Educational Studies, 44(1), 81-98. https://doi.org/10.1 080/03055698.2017.1345677.

Monroy, F., \& Pina, F. (2014). Factors affecting student approaches to learning: A systematic review. Educación $X X 1,17(2), 105-124$.

Mørk, G., Magne, T. A., Carstensen, T., Stigen, L., Åsli, L. A., Gramstad, A., ... \& Bonsaksen, T. (2020). Associations between learning environment variables and students' approaches to studying: A cross-sectional study. BMC Medical Education 20, 120(2020), 1-8. https://doi. org/10.1186/s12909-020-02033-4.

Núñez, R., Paiva, F., Lourenço, A., Cerezo, R., \&Valle,A.(2013).Therelationshipbetween approaches to teaching and approaches to studying: A two-level structural equation model for biology achievement in high school. Metacognition Learning, 8(1), 4777. https://doi.org/10.1007/s11409-0139095-6.

Owusu-Agyeman, Y., \& Fourie-Malherbe, M. (2018). Learning conceptions and priorities of adult engineering students in higher education. Cogent Education, 5(1), 1528700. https://doi.org/10.1080/233118 6X.2018.1528700.

Peterson, E., Brown, G., \& Irving, S. (2010). Secondary school students' conceptions of learning and their relationship to achievement. Learning and Individual Differences, 20(3), 167-176. https://doi. org/10.1016\%2Fj.lindif.2009.12.004.

Purdie, N., \& Hattie, J. (2002). Assessing students' conceptions of learning. Australian Journal of Educational and Developmental Psychology, 2(2002), 1732. 
Ramburuth, P., \& McCormick, J. (2001). Learning diversity in higher education: A comparative study of Asian international and Australian students. Higher Education, 42(3), 333-350 https://doi. org/10.1023/A:1017982716482.

Richardson, J. (2010). Conceptions of learning and approaches to studying among white and ethnic minority students in distance education. British Journal of Educational Psychology, 80(4), 535-556. https://doi. org/10.1348/000709910X489283.

Richardson, J. (2011). Approaches to studying, conceptions of learning and learning styles in higher education. Learning and Individual Differences, 21(3), 288$293 . \quad$ https://doi.org/10.1016/j. lindif.2010.11.015.

Sadi, Ö., \& Dagyar, M. (2015). High school students' epistemological beliefs, conceptions of learning, and self-efficacy for learning biology: A study of their structural models. Eurasia Journal of Mathematics, Science \& Technology Education, 11(5), 1061-1079 https://doi. org/10.12973/eurasia.2015.1375a.

Shen. K., Lee, M., Tsai, C., \& Chang, C. (2016). Undergraduate students' earth science learning: Relationships among conceptions, approaches, and learning selfefficacy in Taiwan. International Journal of Science Education, 38(9), 1527-1547. https://doi.org/10.1080/09500693.2016.1 198060.

Suyitno, I., Pratiwi, Y., \& Martutik, R. (2019). How prior knowledge, prospect, and learning behaviour determine learning outcomes of BIPA students? Cakrawala Pendidikan, 38(3), 499-510. https://doi. org/10.21831/cp.v38i3.27045.

Tsai, P., Chai, C., Hong, H., \& Koh, J. (2017) Students' conceptions of and approaches to knowledge building and its relationship to learning outcomes. Interactive Learning Environments, 25(6), 749-761. https://doi. org/10.1080/10494820.2016.1178653.
Tsai, C. (2004). Conceptions of learning science among high school students in Taiwan: A phenomenographic analysis. International Journal of Science Education, 26(14), 1733-1750. https:// doi.org/10.1080/0950069042000230776.

Tuononen, T., Parpala, A., \& Lindblom-Ylänne, S. (2019). Complex interrelations between academic competences and students' approaches to learning - mixed-methods study. Journal of Further and Higher Education, 44(8), 1080-1097. https://doi. org/10.1080/0309877X.2019.1648776.

Umapathy, K., Ritzhaupt, A., \& Xu, Z. (2020). College students' conceptions of learning of and approaches to learning computer science.JournalofEducational Computing Research, 58(3), 662-686. https://doi. org/10.1177\%2F0735633119872659.

Valadas, S. (2013). Conceptions of learning, approaches to learning and cognitive development: Students profiles in a Portuguese higher education institution. International Journal of Developmental and Educational Psychology, 2(1), 107116. http://www.redalyc.org/articulo. oa? id=349832329010.

Vettori, G., Vezzani, C., Bigozzi, L., \& Pinto, G. (2018). The mediating role of conceptions of learning in the relationship between metacognitive skills/strategies and academic outcomes among middleschool students. Frontiers in Psychology, 9, 1985, 1-13. https://doi.org/10.3389/ fpsyg.2018.01985.

Wallace, S. (2009). A Dictionary of Education. Oxford, CA: Oxford University Press.

Yang, X., Leung, F. \& Zhang, S. (2019). Junior Secondary School Students' Conceptions of and Approaches to Learning Mathematics and Their Relationships in Mainland China. Sustainability Journal, 11(9), 1-13. https://doi.org/10.3390/ su11092476.

Yildirim, A., \& Simsek, H. (2005). Qualitative research methods in social sciences $\left(5^{\text {th }}\right.$ ed.). Ankara: Seçkin Publications. 